\title{
Development and Implementation of a Flexible Model Architecture for Hybrid-Electric Aircraft
}

\author{
John Batteh $^{1} \quad$ Jesse Gohl $^{1} \quad$ Michael Sielemann $^{2} \quad$ Peter Sundstrom $^{3} \quad$ Ivar Torstensson $^{3}$ \\ Natesa MacRae ${ }^{4} \quad$ Patrick Zdunich ${ }^{4}$ \\ ${ }^{1}$ Modelon Inc., USA, $\{$ john.batteh, jesse.gohl $\} @$ modelon.com \\ ${ }^{2}$ Modelon Deutschland GmbH, Germany, \{michael.sielemann $\}$ @modelon .com \\ ${ }^{3}$ Modelon AB, Sweden, p peter. sundstrom, ivar.torstensson $\}$ @modelon.com \\ ${ }^{4}$ National Research Council Canada, Canada, \{Natesa.MacRae, Patrick.Zdunich\}@nrc-cnrc.gc.ca
}

\begin{abstract}
This paper describes the implementation of a flexible, modular, hybrid-electric aircraft modeling architecture for the development of a virtual and physical demonstrator system that will be used in the advancement of sustainable mobility systems by the National Research Council of Canada (NRC). The initial modeling architecture was established in Modelica based on the NASA X-57 electric flight demonstrator aircraft. A series of models were assembled from a high level aircraft system architecture to mimic the initial developmental path from the baseline conventional aircraft to the X-57 electric aircraft variant. The multi-physics component models describe the aircraft dynamics and performance, integrated with the relevant mechanical, electrical, and thermal dynamics of the electric aircraft power train. The proposed modular architecture allowed the simulation of three different aircraft configurations with different degrees of electrification, demonstrating its effectiveness and versatility in the design and development of hybrid-electric aircraft.
\end{abstract}

Keywords: aerospace, hybrid-electric aircraft, electrification, electric propulsion, thermal

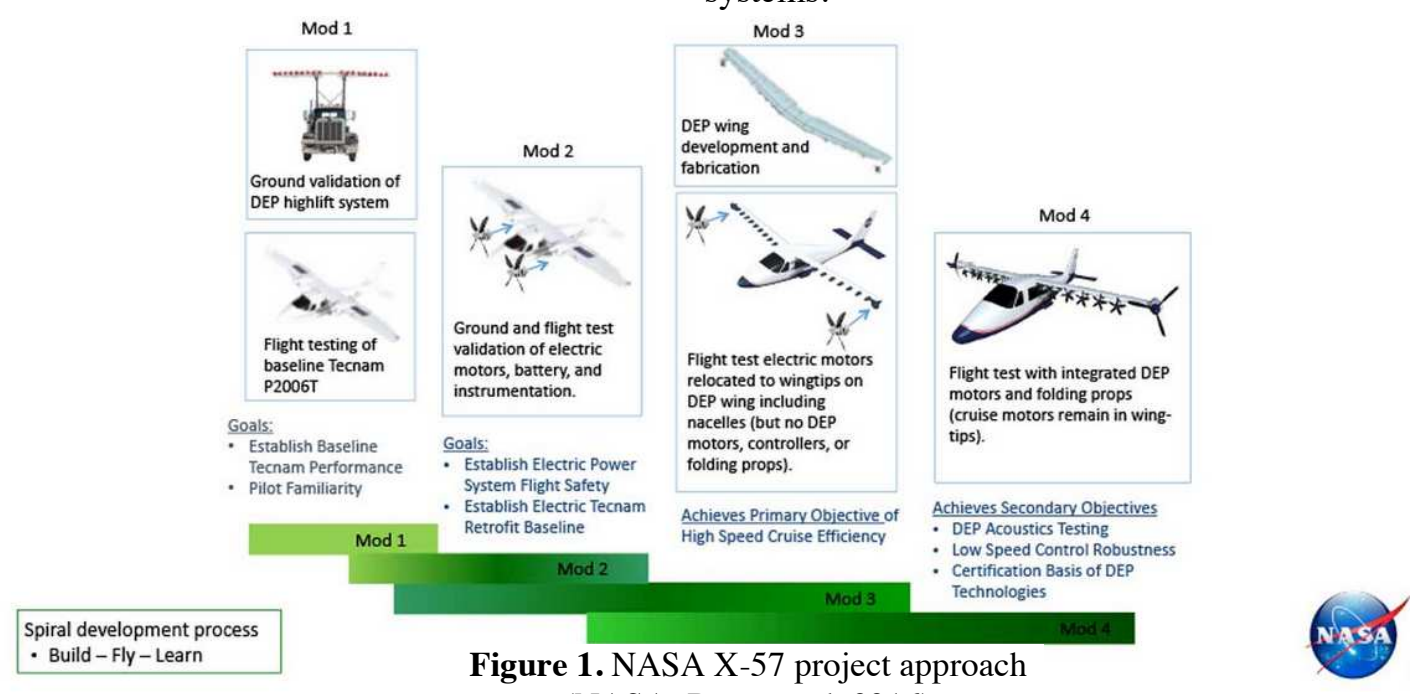

(NASA: Borer et al, 2016)

\section{Introduction}

Triggered by the demand for reduced emissions / fuel burn, external noise, and maintenance costs, the aircraft industry is actively pursuing the concepts of 'more electric' and 'fully electric aircraft'. Although the first manned electric aircraft flight took place in 1973 with the Militky MB-E1 (Taylor, 1974), a growing trend has emerged in the past decade with the increased electrification of the Boeing 787 Dreamliner (Boeing, 2018), the all-electric Airbus E-Fan (with recent plans for the collaborative development of the E-Fan X between Airbus, Rolls Royce and Siemens) (E-Fan/E-Fan X, 2017), the Pipistrel Alpha Electro (Pipistrel, 2018), and the ongoing development of the National Aeronautics and Space Administration (NASA) X-57 (NASA, 2018). Current advancements in the technologies that support this trend include innovations in the fields of power electronics, sensors, high density electric motors, energy storage, and power generation. In addition, advances in modeling and simulation software have led to the development of flexible, modular model architectures, which provide a uniquely efficient way to manage the challenges inherent in the modeling of advanced multi-domain systems. 
This paper describes the development and implementation of a flexible, modular model architecture for hybrid-electric aircraft.

\subsection{Model Architecture Application}

Electrically propelled and powered aircraft represent a disruptive technology that, from an aviation safety and reliability perspective, requires an evolutionary technological development path. To support this development, the NRC has initiated two parallel 'sister' projects that will provide both a virtual and physical test platform for hybrid-electric aircraft system innovation. The first is a Sustainable Mobility Systems (SiMS) Virtual Demonstrator - a multidisciplinary virtual prototyping tool that will support the development of hybrid-electric aircraft throughout the system development life cycle. This tool will be used to support the evaluation of individual and integrated component-level technologies associated with hybrid-electric aircraft, including power generation, storage, transmission, conversion, and consumption components. It will also provide support for system and component characterization, optimization, trade studies, performance evaluation, and failure modes and effects analysis. The second is the development of a Hybrid Electric Aircraft Testbed (HEAT) - an airborne electric propulsion test-bed demonstrator that will be used to evaluate various hybrid-electric propulsion systems / configurations and gather experimental data to inform evolving certification requirements. Initially, SiMS will act as a virtual prototyping tool for the design and development of the HEAT physical demonstrator. In turn, HEAT will provide data to validate or tune system and component level models used by SiMS. Together, these systems will provide a dedicated research platform to advance hybrid-electric aircraft development and certification.

\subsection{Developmental Approach}

For the creation of SiMS, a custom aircraft model architecture was developed in Modelica using a suite of Modelon libraries: Aircraft Dynamics Library, Electrification Library, and Liquid Cooling Library (Modelon AB, 2018). To define a reasonable starting point for the modeling framework, the architecture was established using a real-world electric aircraft: the NASA X-57. The high availability of technical data related to the NASA X-57 project provided a unique opportunity to demonstrate the effectiveness of these libraries in supporting the development of a custom electric aircraft model architecture. In addition, since the X-57 is being developed in stages (Tecnam, 2018), it provided the opportunity to demonstrate the ability of the model architecture to adapt to configuration changes starting from a conventional baseline aircraft the Tecnam P2006T (Mod 1) and leading to a fully modified electric aircraft (Mods $2 \& 3$ ). Note that the $\mathrm{X}-57$ is currently in development with flight testing of Mod 3 targeted for mid-2020. A model of the final configuration (Mod 4) was not developed.

\section{Model Libraries}

The Aircraft Dynamics Library from Modelon is a new library offering that includes a full, flexible model architecture and compatible component models for modeling aircraft systems. The library includes a powerful sizing model for implementation of the aircraft systems and can support a range of analyses integrating:

- Specification of aircraft geometry

- Flight dynamics

- Propulsion dynamics

- Aerodynamics

- Energy and fuel consumption

- Fuel dynamics

- Thermal dynamics

- Environmental control

- Auxiliary power

- Actuation systems

- Landing gear

- Flight controls

- Flight maneuvers and mission profiles

The library provides a $6 \mathrm{DOF}$ representation of the aircraft flight dynamics using aircraft geometry and the distributed mass and inertia of the individual subsystems (Stengel, 2004). The top level aircraft subsystem decomposition is shown in Figure 2, including the airframe, power systems, and general aircraft systems (including avionics, flight deck and cabin systems, etc). These subsystem models can be further broken down into individual components.

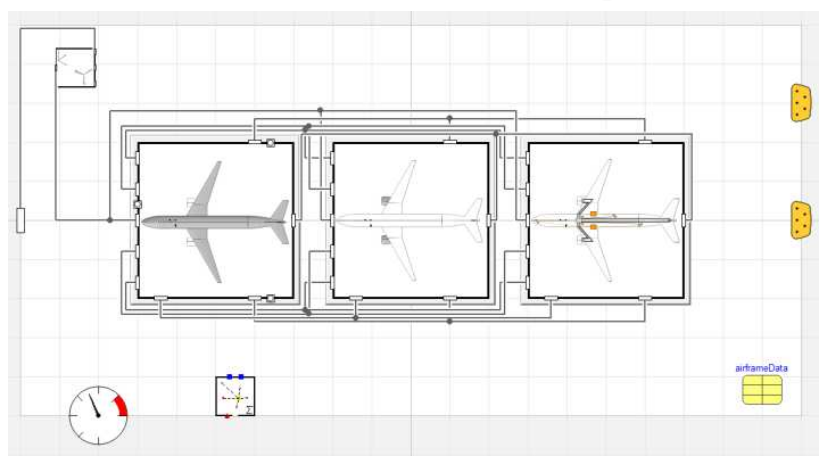

Figure 2. Aircraft decomposition in Aircraft Dynamics Library

Figure 3 shows the next level of decomposition of the airframe subsystem where the fuselage, wings, tail, landing gear, and aerodynamics are specified. 


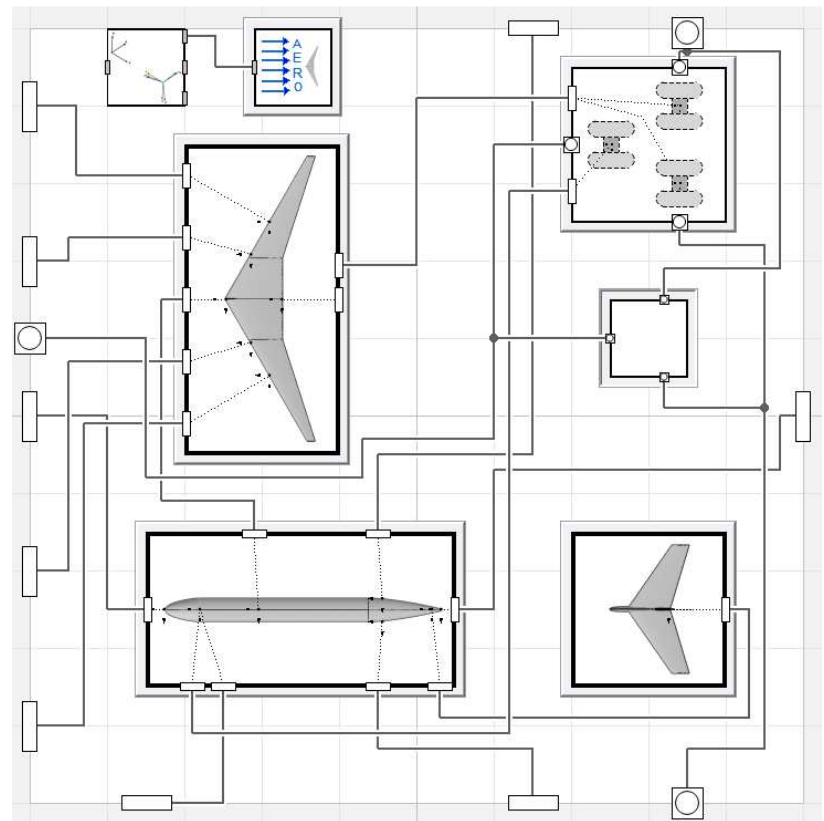

Figure 3. Architecture of the airframe subsystem

Figure 4 shows the architecture of the power subsystem, where the Electrification and Liquid Cooling libraries can be applied, and where the engines, electrical systems, actuation systems, auxiliary power systems and fuel systems are specified.

The sizing model (Kroo, 2001) enables the realization of different types of aircraft quickly. Users are provided with configurable options for input of the different parameters needed to specify the aircraft geometry. This capability allows the model to estimate missing information where minimal data is available (in order to quickly establish a working aircraft model), while also providing options for input of detailed geometry, where this data is known.

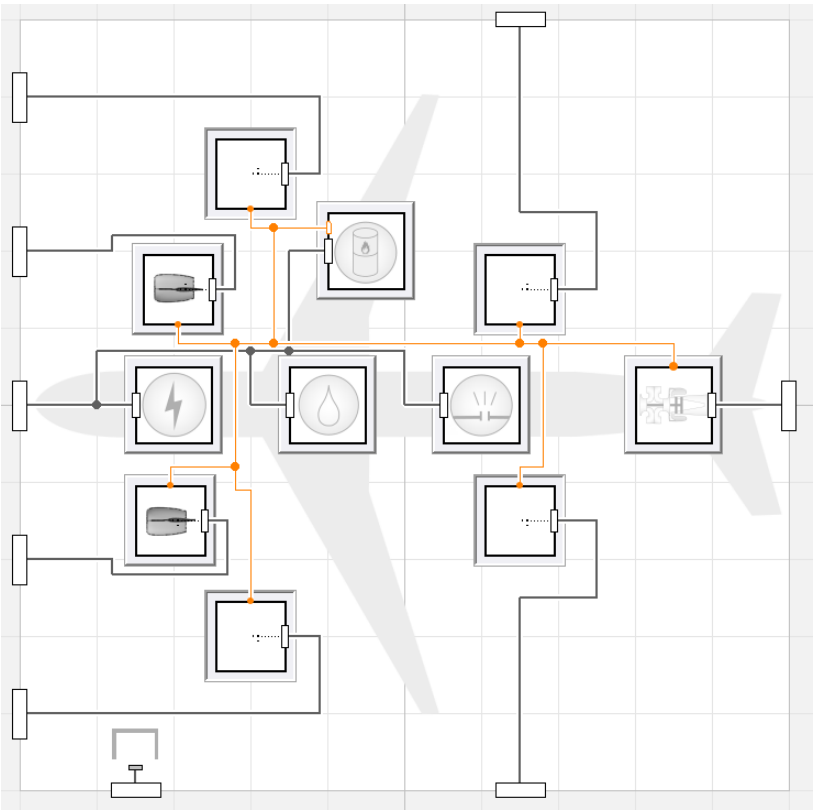

Figure 4. Architecture of the power subsystem
Models are built by configuring templates, and models of different levels of fidelity can easily be implemented within the flexible model architectures. Further details of model implementation will be provided in the following sections describing the implementation of the Tecnam P2006T and X-57 models. Note that the Aircraft Dynamics Library integrates with other Modelon libraries including Jet Propulsion Library, Fuel Systems Library, Environmental Control Library, Hydraulics Library, Pneumatics Library, and Liquid Cooling Library.

\section{$3 \quad \mathrm{X}$-57 Modeling and Simulation}

This section describes the development and implementation of the P2006T and X-57 models. The development of these models roughly followed the project approach shown in Figure 1 with the initial development of the baseline P2006T model (Mod 1), followed by various developmental milestones leading to the X-57 (up to Mods $2 \& 3$ ).

\subsection{Aircraft Overview}

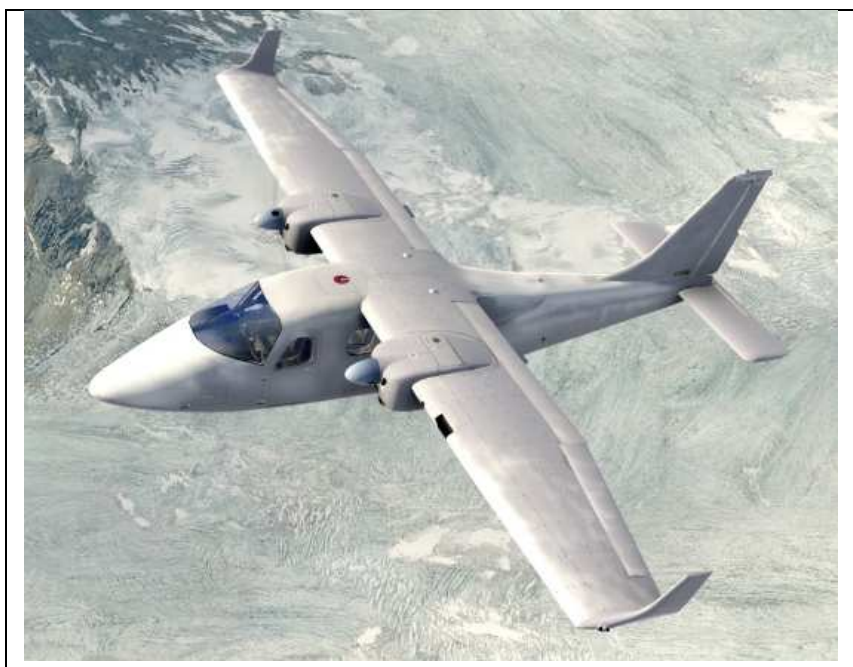

(a) Tecnam P2006T

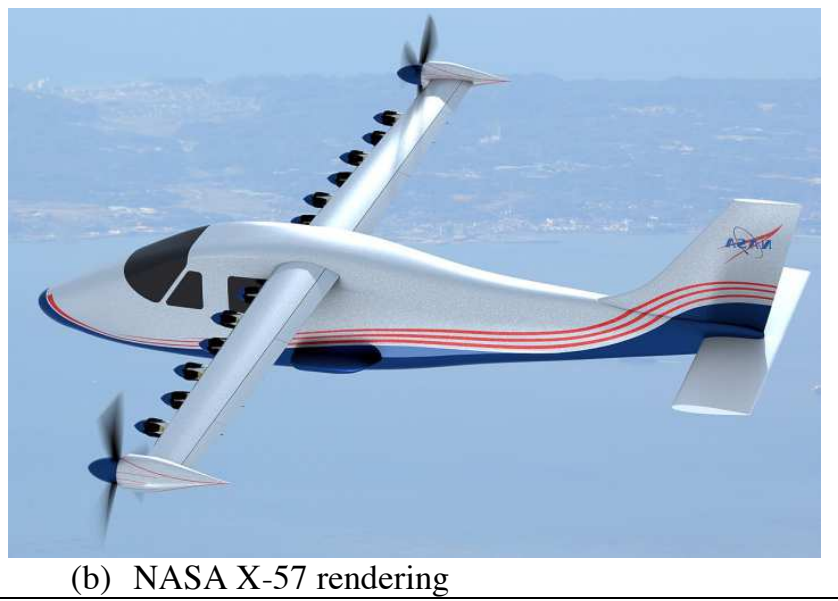

Figure 5. Tecnam P2006T and NASA X-57 aircraft

The Tecnam P2006T is a twin-engine four-seat general aviation aircraft. Shown in Figure 5a, the P2006T has a 
high wing and twin Rotax 912 S3 $100 \mathrm{hp}$ four cylinder internal combustion engines. The engines drive twobladed constant speed propellers capable of full feathering. Nominal specifications include a maximum cruise speed of $77 \mathrm{~m} / \mathrm{s}(150 \mathrm{kt}), 1239 \mathrm{~km}$ range, and fuel consumption of $17 \mathrm{~L} / \mathrm{h}(4.5 \mathrm{gal} / \mathrm{hr})$ per engine (Tecnam, 2018).

The NASA X-57 aircraft is a heavily modified Tecnam P2006T and is being developed as part of the Leading Edge Asynchronous Propeller Technology (LEAPTech) project (NASA, 2018), initiated in 2014. Shown in Figure 5b as an artist's rendering, the X-57 features two wing tip cruise motors and six small electric motors distributed along the leading edge of each wing. The wing of the X-57 is optimized for the high-speed cruise condition, and therefore, its area is substantially reduced and aspect ratio increased compared to the original Tecnam P2006T. In order to produce the necessary lift at the lower speeds of takeoff and landing, a trailing edge flap is deflected, and the motors distributed along the leading edge are operated to increase the flow velocity over the wing and therefore increase lift. These lift augmentation propellers fold snugly along the motor nacelles when not in use during cruise to reduce drag.

\subsection{P2006T Modeling and Results}

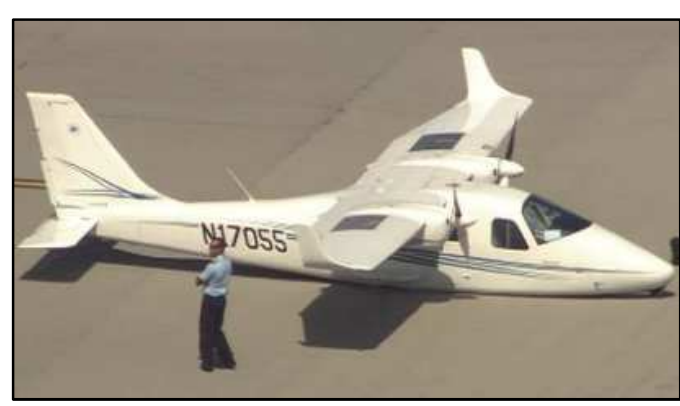

(a) Tecnam P2006T

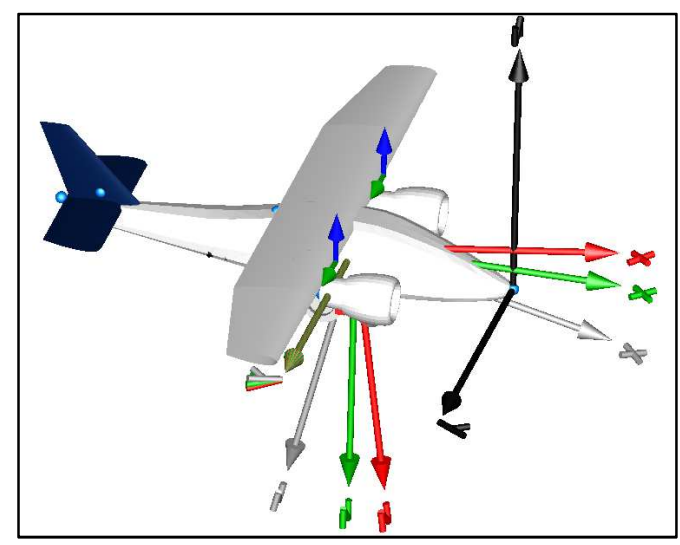

(b) Tecnam P2006T rendering

Figure 6. Actual and animation of P2006T aircraft

The first step in the development of the X-57 Modelica model was the creation of a baseline model of the P2006T aircraft (Mod 1). The sizing model from the
Aircraft Dynamics Library was used to provide reasonable implementations of the various aircraft subsystems for modeling the airframe. A simplified, high level model of the P2006T powertrain was assembled, and a surrogate turboprop model was used to drive the P2006T. A default aerodynamic model provided by the sizing model was used to provide first cut estimates for the aerodynamic forces based purely on the geometry (using information and technical drawings from the manufacturer's website (Tecnam, 2018)).

The ability to animate the entire aircraft is natively integrated into the individual airframe models generated by the sizing model (see Figure 6). This animation can provide feedback on the aircraft dynamics as well as visual feedback on the geometric specification of the aircraft. Users can then leverage the animation to refine the geometric parameters provided directly or entered into the sizing model.

Figure 7 shows the top level P2006T modeling experiment. This experiment contains the aircraft model and a controller implementation that controls the aircraft elevator and thrust to provide the specified aircraft velocity and altitude profiles. The simulation was run with a cruise velocity set-point of $70 \mathrm{~m} / \mathrm{s}$ ( 136 knots). The resulting aircraft response with respect to velocity, height, drag and lift coefficients, and thrust force are shown in Figure 8.

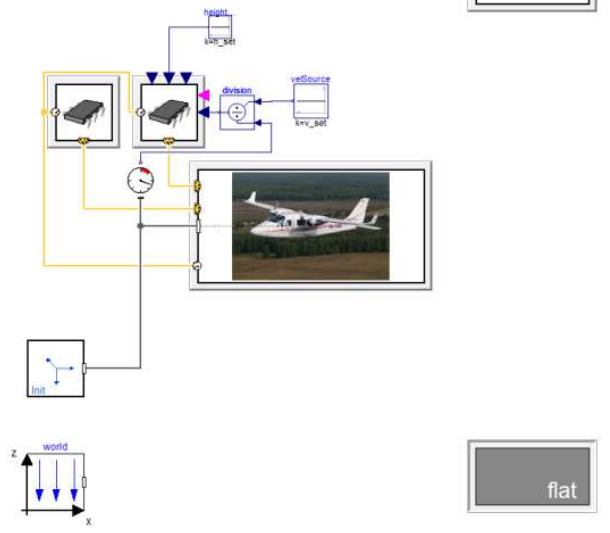

Figure 7. P2006T flight experiment

The simulation resulted in a shaft power requirement (thrust force $\mathrm{x}$ velocity) of $124 \mathrm{~kW}$ (167 $\mathrm{hp}$ ), which the combined shaft power of the Tecnam's two Rotax power plants is capable of producing (150 $\mathrm{kW}$ or $200 \mathrm{hp}$ ); the aircraft drag is implicit in the power requirement and is therefore also deemed acceptable. The lift coefficient of $\mathrm{C}_{\mathrm{L}}=\sim 0.5$ is a reasonable value for an aircraft of this type and is consistent with the lift coefficient obtained in cruise condition under test (Nicolosi, 2010). 

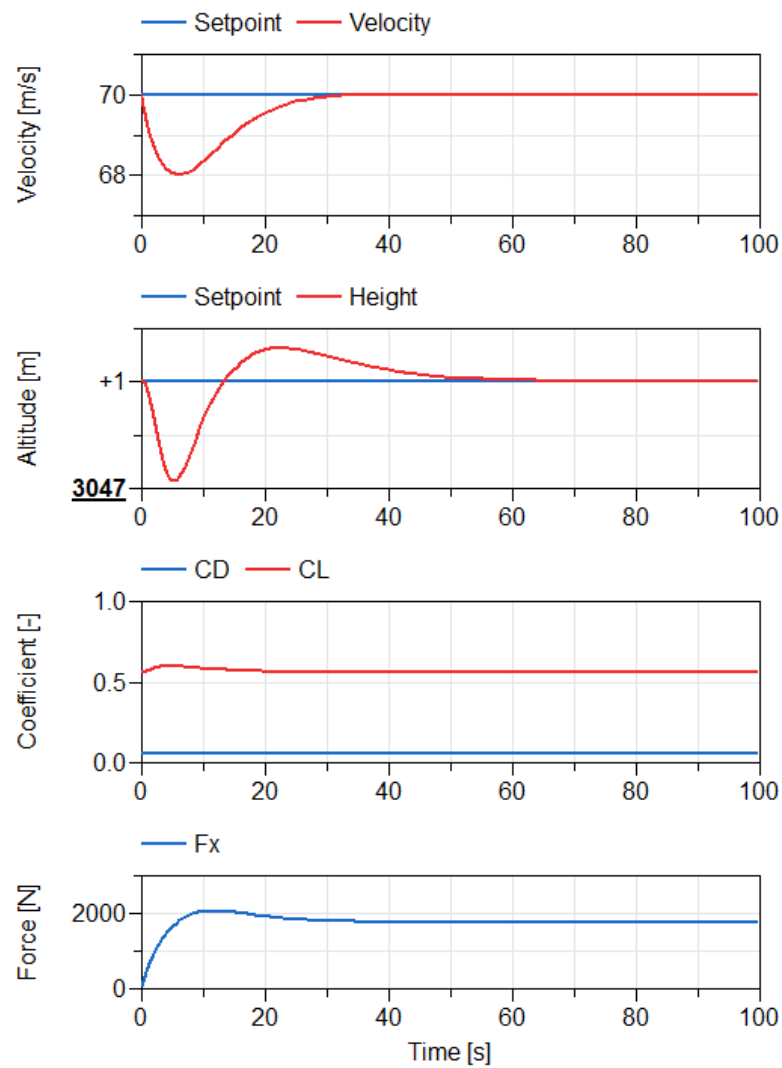

Figure 8. P2006T simulation results

\subsection{X-57 Modeling and Results}

With a reasonable baseline model for the P2006T achieved, the model was adapted to represent the X-57 in a series of model-based development steps. The modeling steps that parallel the project approach shown in Figure 1 are described in this section.

X-57 Mod 2 involves the development and testing of the electric powertrain, first on the ground and then integrated into the P2006T airframe. The X-57 electric powertrain was modeled using the Electrification Library and cooling system components from Liquid Cooling Library (Modelon AB, 2018). The modeling approach is similar to that described in (Falck, 2017), including thermal models to capture thermal interactions and potential thermal operating constraints for the electric powertrain. These models are focused on overall energy efficiency and thus use an averaged approach for the power electronics (detailed models of electrical system operation with switching is not required). This simplification also improves the computational efficiency of simulations performed over an entire mission profile. Though the specification of the X-57 powertrain is still under development, the electric powertrain model includes the following:

- Dual 120 Ah battery packs with 128 cells in series, 40 cells in parallel

- Two $60 \mathrm{~kW}$ electric motors

- Power inverters

- Lossy electric cables
- Two $1.5 \mathrm{~m}$ propellers

- Air cooled thermal system with flow from motor to inverter

Figure 9 shows one half of the X-57 electric powertrain on a test bench, including the thermal system and propeller. The aircraft speed and ambient air density are applied as boundary conditions, and the motor torque command and propeller pitch angle are applied as commands. The propeller performance is modeled after (Wainausky, 1989).

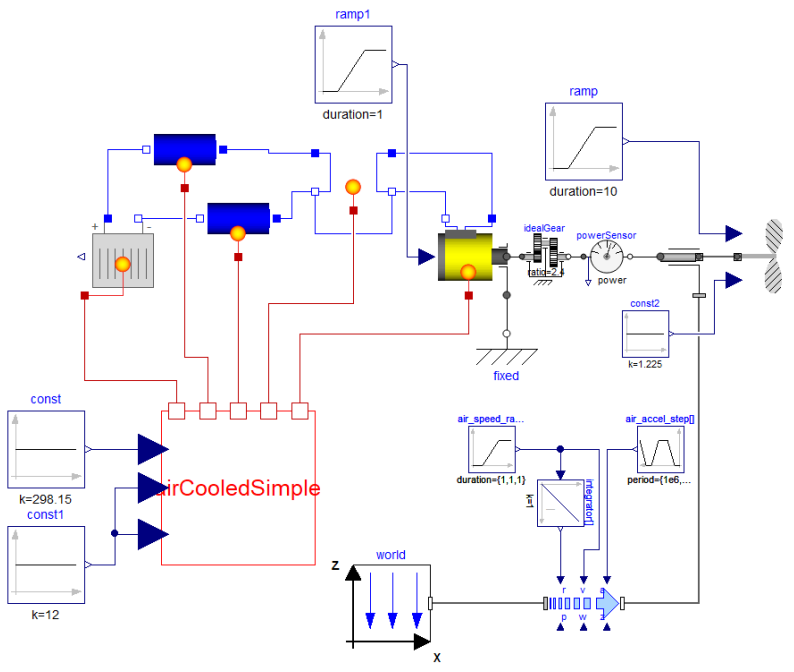

Figure 9. X-57 electric powertrain test bench

This test bench allows for model-based development of the electric powertrain for system sizing and integration, energy consumption, and controls development.
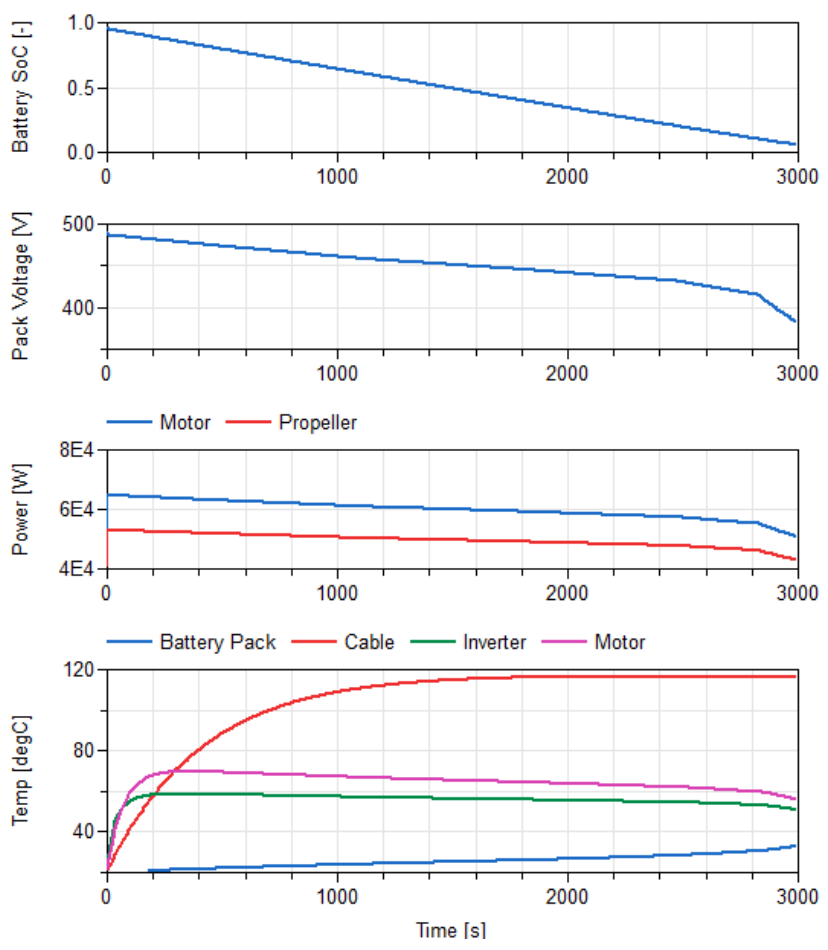

Figure 10. Full battery discharge, full power, $V=50 \mathrm{~m} / \mathrm{s}$ 
Figure 10 shows results from the powertrain test bench. These simulations were run with the aircraft speed set at $50 \mathrm{~m} / \mathrm{s}$ and full power commanded from the motor. This simulation showed that after $3000 \mathrm{~s}$, the battery state of charge went from 0.95 to 0.06 . The pack voltage drops as the state of charge decreases due to changes in the battery voltage capability and the increase in resistance; thus, the power delivered by the motor and power produced by the propeller also drop. The battery pack temperature increases over the entire simulation due to the large thermal capacitance of the battery pack. When the state of charge drops, there is more heat generated by the battery pack due to increased electrical resistance and thus an increase in the temperature rise rate. Temperatures for the cable, inverter, and motor are also shown. This type of simulation can be used for system sizing and for estimating potential aircraft range for a specific electric powertrain configuration.

Figure 11 shows results from a blade pitch angle ramp at full power command, with aircraft speed at 50 $\mathrm{m} / \mathrm{s}$. As the blade pitch angle increases, the propeller power drops to maintain the constrained air speed condition. The plot shows the power out of the battery pack, delivered by the motor at the shaft, and delivered by the propeller as thrust power.
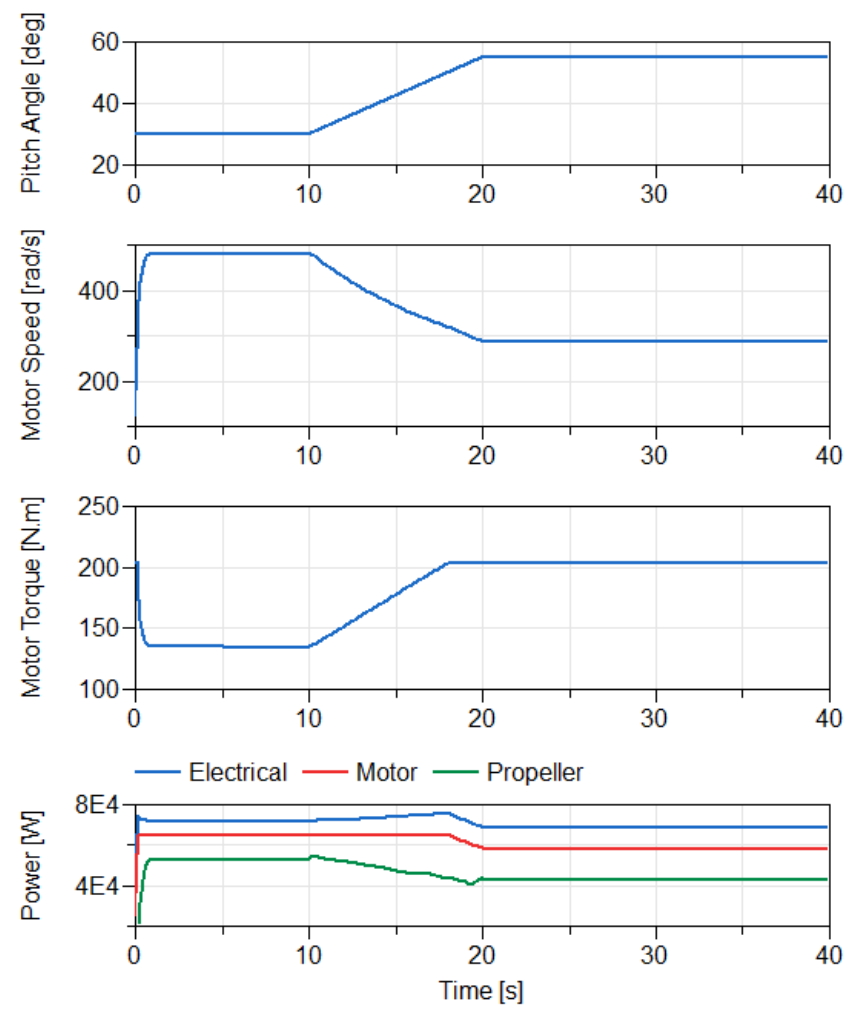

Figure 11. Propeller blade angle ramp, full power command, aircraft speed $50 \mathrm{~m} / \mathrm{s}$

This type of simulation can be used to develop optimum system operation strategies for different aircraft operating conditions and power demands.
To facilitate integration of the electric powertrain into the aircraft model, a new power template for Aircraft Dynamics Library was created, as shown in Figure 12. As compared to the original power template shown in Figure 4, this new power template incorporates the following changes to allow drop-in replacement of the various electric powertrain subsystems without requiring any additional connections between subsystems:

- Addition of electrical bus connectors to the engine and electric systems (blue connections)

- Addition of thermal bus connectors to the engine and electric systems (red connections)

- Addition of a new thermal subsystem with electrical and thermal bus connectors

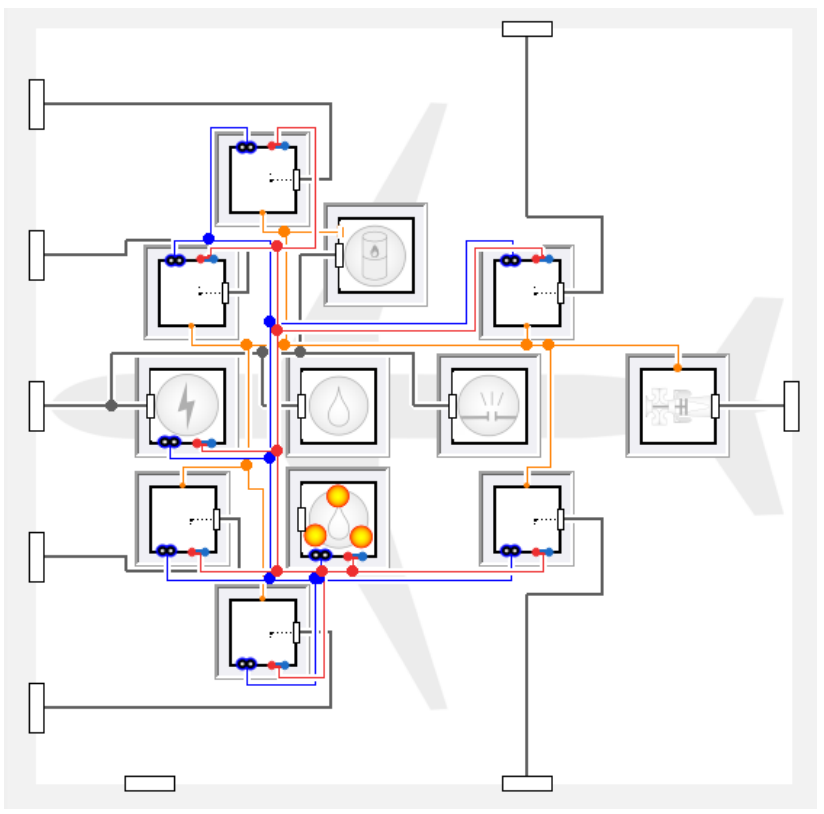

Figure 12. New Power template for electric aircraft

As described in Figure 1, Mod 2 progresses from ground testing of the electric powertrain to integration of the electric powertrain into the P2006T airframe to replace the conventional engine powertrain. Using the new power template shown in Figure 12, the electric powertrain shown in Figure 9 was integrated as follows:

- electric subsystem contains the battery pack (1 for each side) for the cruise motors

- engine 2 and engine3 subsystems contain the cable, inverter, motor, and propeller for the cruise motors (1 for each side)

- thermal subsystem provides cooling to components (one thermal system in total to more easily handle the connections between systems on the thermal side)

With the power system implemented, a simple redeclare was all that was needed to create the 
model variant of the P2006T with the electric powertrain as shown in Figure 13.

After the initial testing of the electric powertrain in the P2006T airframe, Mod 3 in the X-57 development plan includes the modification of the P2006T airframe to integrate the Distributed Electric Propulsion (DEP) wing design. These same changes were implemented in the model to develop the X-57 Mod 3 aircraft.

model P2006TElectric_Aircraft "P2006T with electric powertrain" extends X57.Aircraft.TecnamP2006T(redeclare replaceable

X57_Power power);

end P2006TElectric_Aircraft;

Figure 13. Modelica code for electric P2006T aircraft

The final X-57 configuration will include the distributed electric propulsion system and a cruiseoptimized wing geometry with a program goal of a $5 \mathrm{x}$ reduction in cruise energy consumption when compared with the baseline P2006T (Deere, 2017). For the purposes of the X-57 model in this work, only the cruise motors were considered, as the Mod 3 focus is on understanding energy usage under cruise conditions when the high lift motors are not active. The new wing geometry was implemented based on the geometric specification in (Deere, 2017). The extensive CFD analysis conducted on the proposed X-57 wing designs (Deere, 2017) was used to create a custom aerodynamics model using the Aircraft Dynamics Library. This new table-based lift and drag model was implemented with coefficients as a function of angle of attack. The X-57 aircraft model was then constructed as a variant of the P2006T by redeclare of the airframe, aerodynamics model, and power subsystem as shown in Figure 14.

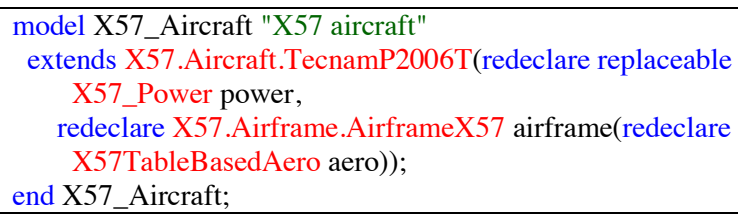

Figure 14. Modelica code for $X-57$ aircraft

The animation for the X-57 aircraft is shown in Figure 15. Note the visual depiction of the new wing design as compared to the P2006T in Figure 6. The $\mathrm{P} 2006 \mathrm{~T}$ wing area is reported as $159 \mathrm{ft}^{2}$ with an aspect ratio of 8.8 as compared to the simulated $\mathrm{X}-57$ design with wing area of $67 \mathrm{ft}^{2}$ and an aspect ratio of 15 .

The X-57 Mod 3 flight experiment is shown in Figure 16. The model includes the X-57 Mod 3 aircraft and a controller. The controller acts on motor torque, propeller blade angle, and aircraft elevator to achieve a desired height, propeller speed, and aircraft speed. Simple PID controllers were sufficient for targeting cruise operating conditions.

Figure 17 shows results from a velocity ramp for the $\mathrm{X}-57$, from $60 \mathrm{~m} / \mathrm{s}$ to $75 \mathrm{~m} / \mathrm{s}$ with the propeller speed command at a constant $2250 \mathrm{RPM}$. As expected, for a constant speed propeller, the pitch angle and the battery pack, motor, and propeller power increase with an increase in aircraft velocity.

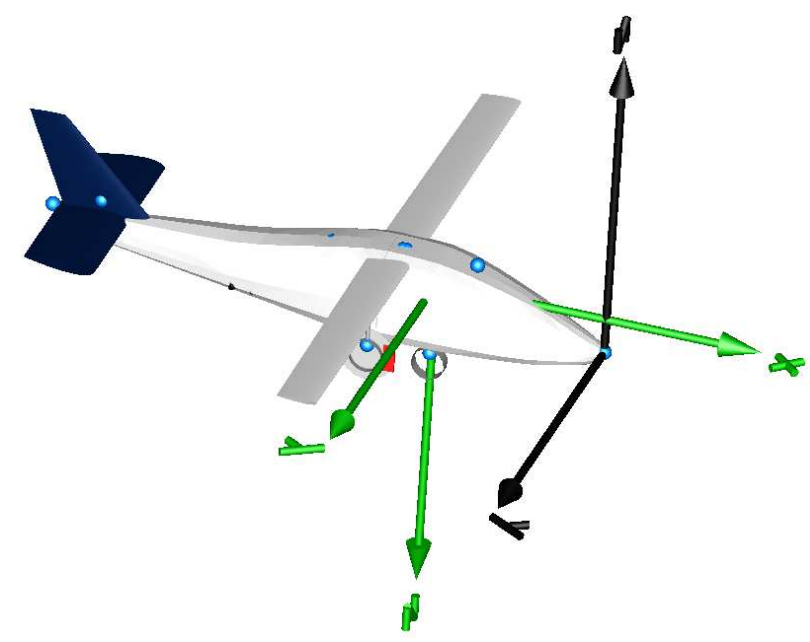

Figure 15. X-57 animation

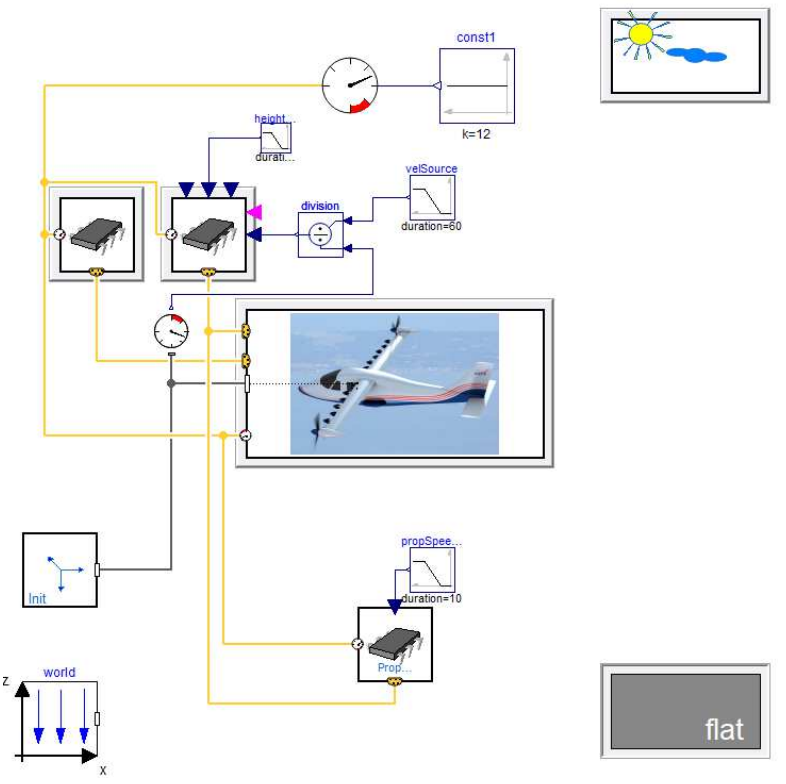

Figure 16. X-57 flight experiment

Figure 18 shows the sensitivity of the battery state of charge to the drag coefficient for the X-57 wing design with the same velocity ramp simulation shown in Figure 17. The variations in drag coefficient were achieved via a multiplier of $1,1.1,1.25,1.4$, and 1.5 on the table-based drag values.

Figure 19 shows the sensitivity of the power consumption to the aircraft altitude using the same velocity ramp conditions simulated previously. The standard atmosphere model in Aircraft Dynamics Library provides atmospheric conditions that vary with altitude. These simulations were run at altitudes of $3048 \mathrm{~m}, 1500 \mathrm{~m}$, and $250 \mathrm{~m}$, where the results are primarily driven by the increase in density at lower 
altitudes and thus, higher drag. Because the lift is also affected by the density, there is an interaction with the aircraft angle of attack, an effect that is not seen when varying the drag coefficient in Figure 18.
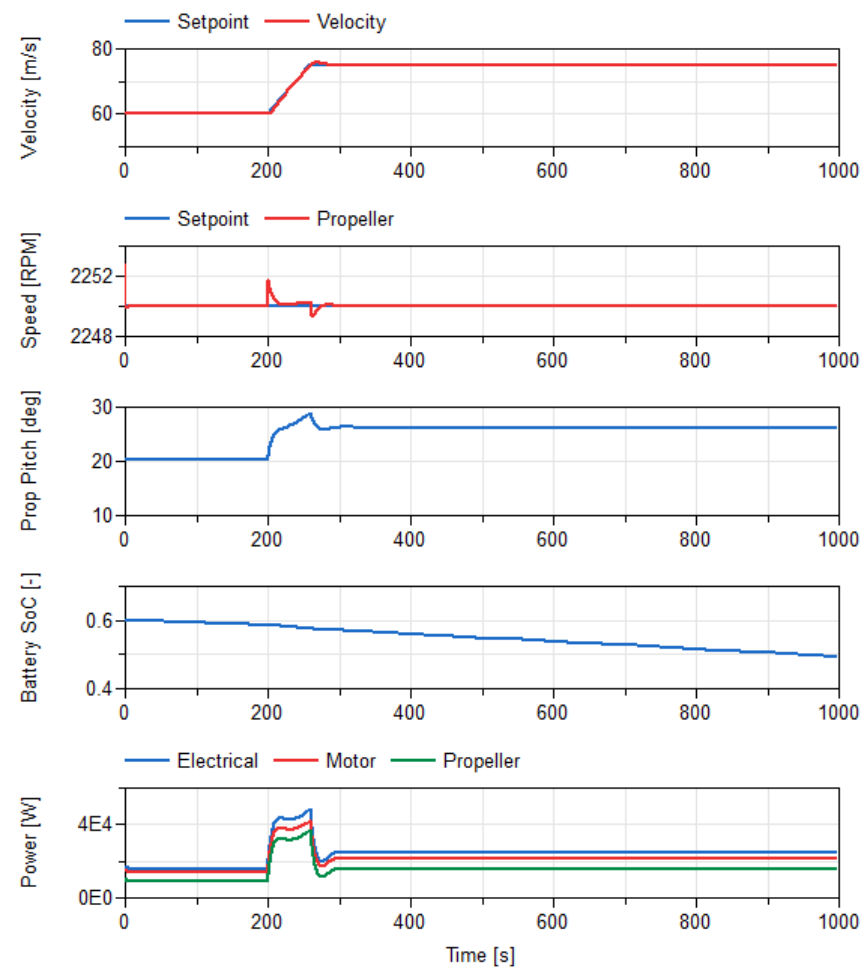

Figure 17. X-57 velocity ramp, constant height

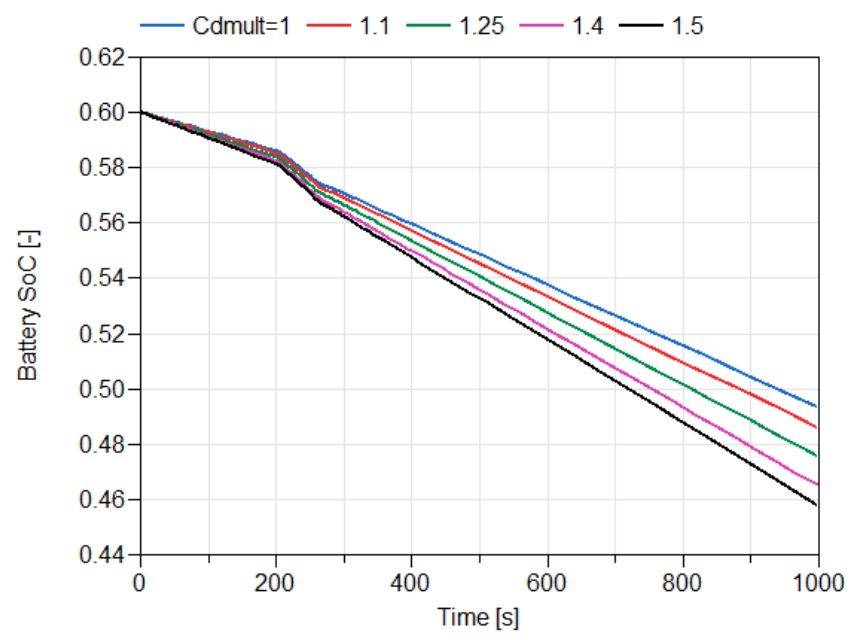

Figure 18. Battery state of charge sensitivity to drag with velocity ramp
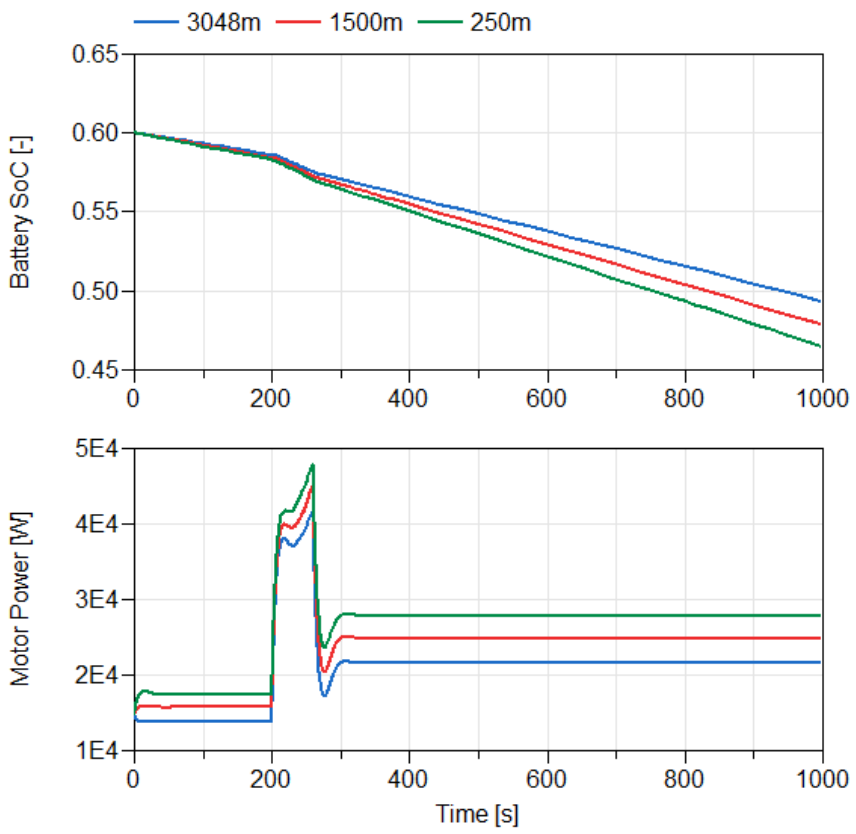

Figure 19. Power consumption sensitivity to aircraft altitude with velocity ramp

\section{Summary}

The move towards 'more electric' and 'fully electric aircraft' has significantly expanded the design space for aircraft systems. In order to support this paradigm shift in aircraft design, a multi-physics modeling approach that captures the relevant mechanical, electrical, and thermal dynamics was undertaken. This approach provides the framework for rapid model variant development and for performing a range of analyses of multi-domain systems. Analyses ranging from electric powertrain test benches to integrated electric aircraft performance were performed using a coordinated suite of Modelon libraries, focusing on Mod 1 to Mod 3 of the X-57 project for cruise efficiency demonstration. The Mod 3 model variant can be extended in future work to include the fully distributed high lift electric propulsion system. With a full model, an extended range of mission profiles, including takeoff and landing can be simulated.

As a result of this work, the underlying framework, power train model architecture, and new electrification model templates have been developed and demonstrated, and will be used to support the continued advancement of the virtual (SiMS) and physical (HEAT) demonstrator systems.

\section{Acknowledgements}

The authors would like to thank Jim Claesson for his support with the library releases for this effort and Abhilash Kumar for his work on these models. 


\section{References}

Boeing, (2013). http://787updates.newairplane.com/787Electrical-Systems/787-electrical-system

Borer, N. K., Patterson, M. D., Viken, J. K., Moore, M. D., Clarke, S., Redifer, M., Christie, R., Stoll, A., Dubois, A., Bevirt, J., Gibson, A., Foster, T., Osterkamp, P., "Design and Performance of the NASA SCEPTOR Distributed Electric Propulsion Flight Demonstrator," AIAA-20163920, 16th AIAA Aviation Technology, Integration, and Operations Conference, AIAA AVIATION Forum, Washington, D.C., June 2016.

Deere, K.A., Viken, J.K., Viken, S.A., Carter, M.B., Wiese, M.R. and Farr, N., "Computational Analysis of a Wing Designed for the X-57 Distributed Electric Propulsion Aircraft", AIAA Aviation Forum, Denver, CO, June 5-9, 2017.

E-Fan / E-Fan X (2017). “Airbus, Rolls-Royce and Siemens develops Hybrid-Electric demonstrator”, https://leehamnews.com/2017/11/29/airbus-rolls-roycesiemens-develops-hybrid-electric-demonstrator/

Falck, R. D., Chin, J. C., Schnulo, S. L., Burt, J. M., and Gray, J. S., "Trajectory optimization of electric aircraft subject to subsystem thermal constraints," 18th AIAA/ISSMO Multidisciplinary Analysis and Optimization Conference, Denver, CO, 2017.

Guy Norris. "Motor Mounting Marks Milestone for NASA's Electric X-plane". Aviation Week \& Space Technology, Sep 5, 2018.

Kroo, I., Shevell, R., "Aircraft Design: Synthesis and Analysis", Desktop Aeronautics, 2001.

Modelon AB, Lund, Sweden. (2018). Aircraft Dynamics Library. $\quad$ http://www.modelon.com/products/modelonlibrary-suite/aircraft-dynamics-library/

Modelon AB, Lund, Sweden. (2018). Electrification Library. http://www.modelon.com/products/modelon-librarysuite/electrification-library/

Modelon AB, Lund, Sweden. (2018). Liquid Cooling Library. $\quad$ http://www.modelon.com/products/modelonlibrary-suite/liquid-cooling-library/

NASA, 2018, "NASA Armstrong Fact Sheet: NASA X-57 Maxwell".

https://www.nasa.gov/centers/armstrong/news/FactSheets/ FS-109.html

Nicolosi, F., De Marco, A., Vecchia, P.D., "Stability, Flying Qualities and Parameter Estimation of a Twin-Engine CS23/FAR 23 Certified Light Aircraft", AIAA Guidance, Navigation, and Control Conference, Toronto, ON, Aug 2$5,2010$.

Pipistrel, (2018). https://www.pipistrel.si/plane/alphaelectro/overview

Stengel, R. F., "Flight Dynamics”, Princeton University Press, 2004.

Taylor, John W. R., "Jane's All the World's Aircraft" Page 573, London: Jane's Yearbooks, 1974-75.

Tecnam, (2018). "P2006T Homepage", http://www.tecnam.com/aircraft/p2006t/

Tecnam, (2018). “ P2006T X-57 MAXWELL NASA

Homepage", https://www.tecnam.com/innovation/p2006tx-57-maxwell-nasa/
Wainausky, H. S., Rohrbach, C., Wynosky, T. A., "Prop-Fan Performance Terminology", SAE Aerospace Technology Conference and Exposition, Long Beach, CA, Oct 5-8, 1987. 